\title{
6.2. TOOLS FOR ENERGY PLANNING IN DEVELOPING COUNTRIES
}

\author{
A. REUTER \\ and \\ A. VOSS \\ Institut fur Kernenergetik und Energiesysteme \\ University of Stuttgart \\ Postfach 801140 \\ 700 Stuttgart 80 \\ FEDERAL REPUBLIC OF GERMANY
}

\begin{abstract}
This paper analyzes the different methods available today for treating major issues in developing countries. The authors discuss problems which have already been addressed by existing models and those that need to be solved.
\end{abstract}

\section{INTRODUCTION}

The energy situation in developing countries is getting more and more complex. While in the industrialized countries a more or less stable level of the energy demand has been reached, developing countries still face twindling growth rates for both, commercial and traditional forms of energy. An adequate energy supply infrastructure which has to cope with this drastically increased demand will have to manage the technological feasibility and reliability problems as well as the financial restrictions associated herewith. The imminent depletion of natural fossil resources, and the irreversible negative effects on the environment leads to a growing awareness of the intertemporal and intergenerational character of the energy problem.

In order to cope with this complex situation, the decision maker has a variety of political instruments at his disposal, which cover measures from direct price and quantity regulations to pricing policies and the promotion of investments in specific economic sectors or favoring the relevant research and development capabilities.

All these activities are influenced by a number of uncertainties, which often are beyond the control of the respective country, like the world prices for energy carriers for example. Also, due to the close interaction of the different economic and social sectors of the economy, one may not regard the specific actions in isolation, but should consider their mutual interference also.

This entity of measures, effects and feedbacks results in a complex and challenging planning task, and requires thorough analyses, which is usually very data intensive. For that reason, computer based planning tools are most suitable to assist in the rational decision making process.

Recent developments in the field of computer based energy planning methods go from specific single fuel, single sector models to more complex integrated systems. Also there is a tendency away from large mainframe computer implementations to user-friendly mini-, micro- and personal computers. 
In this paper it is analyzed, what kind of methods are available today to treat the major energy issues in developing countries, which problems have already been tackled by actually existing models and which are still to be solved. The structures of the different desingns of computerized energy planning tools is explained and the characteristics of an adequate energy planning system, which consists of hardware plus implemented models and a suitable data management system is deducted.

\section{ENERGY MODELS}

The most relevant energy planning tools for both, industrialized and developing countries are models, which mathematically represent one piece of the real system. We classify energy models according to their main purpose into three categories with the indicated modelling methods as shown in Table 1. See Voss et al. (1986).

Table 1

Classification of Energy Models

\begin{tabular}{|l|l|l|}
\hline Energy Planning Models & Purpose & Methodology \\
\hline Energy Demand Model & $\begin{array}{l}\text { Analysis and assessment of } \\
\text { demand variables and } \\
\text { demand structures }\end{array}$ & $\begin{array}{l}\text { Econometrics } \\
\text { Engineering-Process } \\
\text { Approach }\end{array}$ \\
\hline Energy Supply Model & $\begin{array}{l}\text { Identification of fuel and } \\
\text { technology mix }\end{array}$ & Simulation Optimization \\
\hline Energy Economy Model & $\begin{array}{l}\text { Analysis of impact and feed- } \\
\text { backs between energy sector } \\
\text { and the rest of the economy }\end{array}$ & $\begin{array}{l}\text { Simulation Optimization } \\
\text { Econometrics Input-Output } \\
\text { System Dynamics }\end{array}$ \\
\hline
\end{tabular}

\section{Energy Demand Models}

Energy demand models are built to study the sectoral energy demand and its growth on one of the following levels:

- final energy, which refers to the energy delivered to the consumers. (e.g. electricity, gas, oil, etc.)

- useful energy, which refers to energy needed for the service which the consumer wishes to have, (c.g. heat, kinetic energy, etc.)

- energy service, which refers to the served needs of the consumers resulting from the utilization of useful energy plus other services and goods, (e.g. temperate room, cooked meal).

Among the energy demand models, the engineering-process method is widespread, but econometrics is used as well.

\section{Energy Supply Models}

In energy supply models the energy fluws and the associated technologies from extraction through transformation, transportation and distribution up to the end-use level are considered. Either a single fuel (single fuel model), a sector (energy supply sector models) or the energy system as a whole (energy supply system models) is modeled.

A major criticism made to single fuel models is, that the development of the fuel in question is treated in isolation from the rest of the energy system and that these models, therefore, render limited statements on the energy supply system as a whole. See Rath-Nagel and Voss (1981). 
In energy supply system models, all energy flows are included from the primary energy sources through various transformation, transportation, distribution and utilization processes to the different sectoral end-use categories. This network system representation avoids the limitation of single fuel models, but the supply system models are usually more highly aggregated.

The exogenous input for the demand variable is either given in final energy, useful energy or in terms of energy services. The important issues of interfuel substitution, energy conservation and efficiencies improvements in the end-use device can, however, not be handled on the final energy level. If the energy service demand is specified, behavioral factors can be introduced.

Energy supply models generally use simulation or optimization methods, the latter are based on linear and non-linear programming or other optimization techniques.

\section{Energy Economy Models}

Energy-economy models were developed to model the linkages between the energy sector and the rest of the economy including the natural and social environment. They are either built in the form of an integrated modelling system or employ a set of more or less disconnected models.

Energy-economy models allow studying the effects in two directions: from the energy system on the economy and from the economic system on the energy sector. Models which are applied to study the effects in one direction only, for instance by computing capital, labour, material or environmental effects for a given scenario, are called "Impact" models.

The term partial equilibrium models is used for models, that place the energy demand as a dependent variable of the price of energy, which itself is modeled in the economic system. A model is called a general equilibrium model if the energy prices are adjusted to make excess energy demand equal to zero, such that consumers maximize their utility functions while the producers maximize their profits.

The adequacy of the different methods available for the analysis of energy problems have been discussed among economists and engineers extensively. From this discussion it became obvious, that no single method, be it econometric, simulation or optimization can claim to be totally adequate. The proper selection must depend on the problem to be studied.

\section{COMPUTER-BASED TOOLS FOR ENERGY PLANNING}

The analysis of energy systems as well as the development of energy strategies is a data intensive and complex operation, for which computerized tools are predestinated.

The energy models in the sixties were usually programmed as so called stand-alone models. The user - in most cases the programmer himself - enters the necessary data in the specific format, which the model requires. Since every model has it's own data format, the handling of such stand -alone models is rather difficult and troublesome.

The next step in the model development was to add input/output routines to each model, which allows the user, to enter the input data and to present the results in a more comfortable way. This configuration of model plus input/output routine might be called an energy planning tool.

For certain energy planning tasks, like the determination of an optimal energy supply strategy or for regression analysis (two variables regression, multiple regression, time series analysis) and so on, several models are necessary or at least available. Several models for one specific task together with the respective input/output routines are called energy planning modules. 
Stand Alone Model

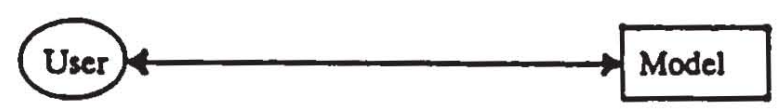

\section{Energy Planning Tool \\ Program}

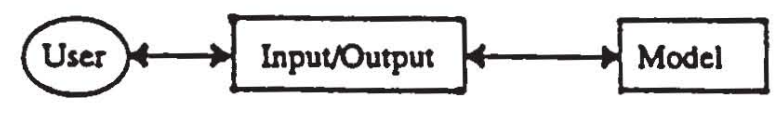

\section{Energy}

Planning Module

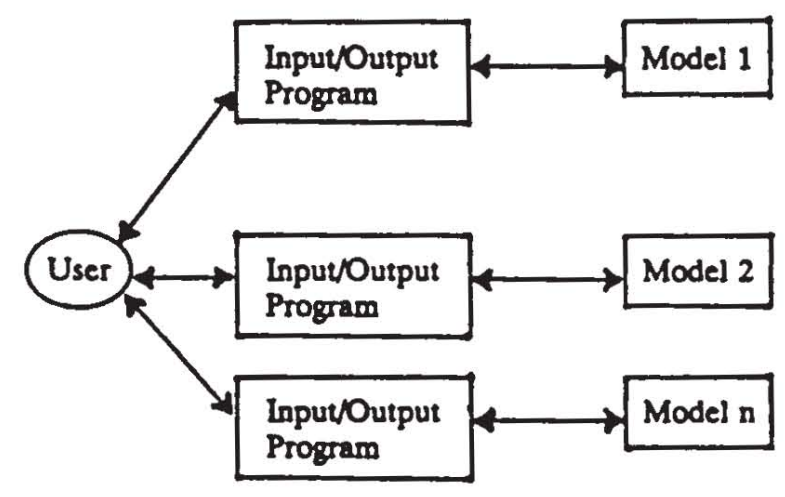

Energy Planning System

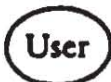

Menu Guide
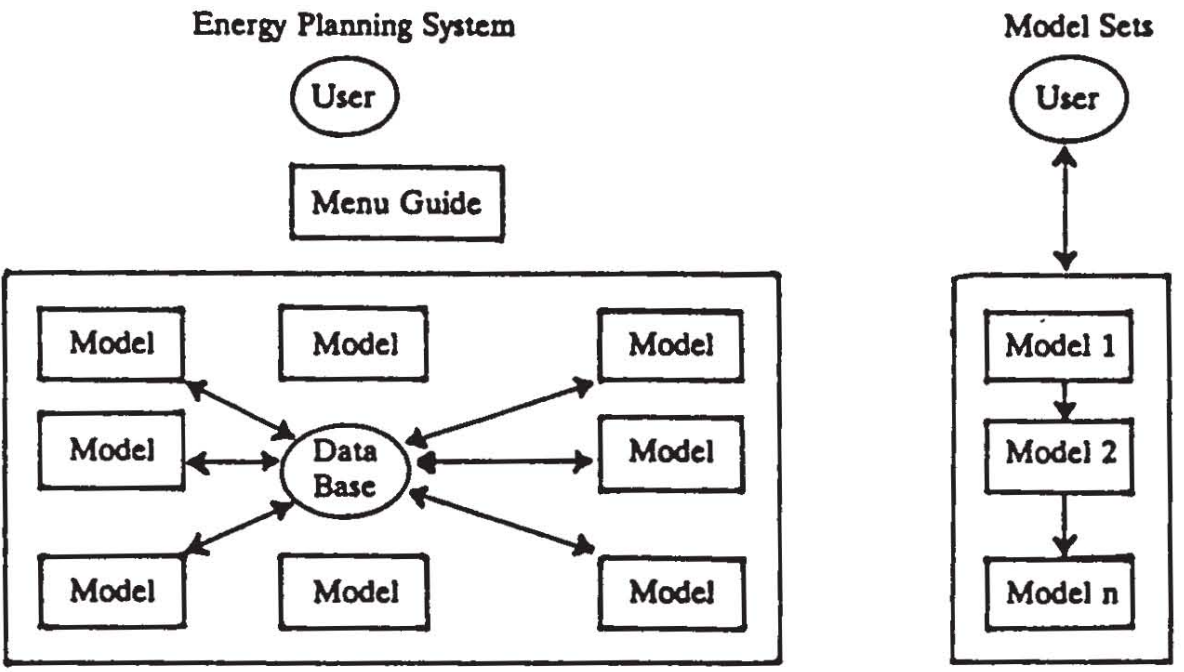

Figure 1: Computer-based Tools for Energy Planning

Actual developments in the field of computerized planning tools concentrate on the implementation of (microcomputer based) energy planning systems and model sets.

Model sets consist of a number of models, which ought to be run in a predefined sequence. The data are transferred automatically from one module to the next one. The IIASA model set is a well known representative of model sets.

Energy planning systems include a set of models, planning tools or modules for different tasks, a data base and a user friendly menu-guide to handle the system. Of course, there is a great variety of such systems from small Personal Computer systems, which concentrate on spread sheet and regression calculations, to sophisticated ones on micro- and minicomputers which include optimization techniques too. MESAP for example is an energy planning system. See Reuter (1986). 


\section{REVIEW OF EXISTING MODELS}

A sample of representative energy planning models, which have been applied in developing countries or which have been designed for developing countries have been reviewed and evaluated to get a rough survey on the actual state of the art in this field. In Table 2 the evaluated models and planning systems are listed.

Table 2

Evaluation List of Energy Models and Planning Systems/Model Sets

\begin{tabular}{|c|c|c|c|}
\hline $\begin{array}{l}\text { Energy Demand } \\
\text { Models }\end{array}$ & $\mid \begin{array}{l}\text { Energy Supply } \\
\text { Models }\end{array}$ & $\begin{array}{l}\text { Energy-Economy } \\
\text { Models }\end{array}$ & $\begin{array}{l}\text { Energy Plan- } \\
\text { ning Systems/ } \\
\text { Model Sets }\end{array}$ \\
\hline $\begin{array}{l}\text { Argonne } \\
\text { Energy } \\
\text { Model } \\
\text { EDE } \\
\text { Energy Re- } \\
\text { quirement Mo- } \\
\text { del } \\
\text { Rural Area } \\
\text { (IDEE) } \\
\text { Long Term } \\
\text { Energy Demand } \\
\text { Forecasting } \\
\text { for Develop- } \\
\text { ing Countries } \\
\text { (Thailand) }\end{array}$ & $\begin{array}{l}\text { Energy } \\
\text { Planning } \\
\text { System Model } \\
\text { (Bogazici) } \\
\text { EFom } \\
\text { Energy } \\
\text { Technology } \\
\text { Assessment } \\
\text { Model (Stan- } \\
\text { ford) } \\
\text { KwU and } \\
\text { Interatom } \\
\text { Models } \\
\text { Less devel- } \\
\text { oped } \\
\text { Countries } \\
\text { Energy System } \\
\text { Network (BNL } \\
\text { MARKAL } \\
\text { MESSAGE II } \\
\text { RETINE } \\
\text { WASP } \\
\text { Development } \\
\text { of Electrical } \\
\text { Network } \\
\text { (CIGRE) }\end{array}$ & $\begin{array}{l}\text { Intertemporal } \\
\text { Mathematical } \\
\text { Model of } \\
\text { National } \\
\text { Economy } \\
\text { with I-o } \\
\text { Technique } \\
\\
\text { Computable } \\
\text { General } \\
\text { Equilibrium } \\
\text { Model for } \\
\text { Mexico } \\
\text { Energy } \\
\text { Economy } \\
\text { Simulation } \\
\text { for oil- } \\
\text { Importing }\end{array}$ & $\begin{array}{l}\text { ENERPLAN } \\
\text { ENVEST } \\
\text { IDEA } \\
\text { LEAP } \\
\text { ENPEP } \\
\text { WOIL } \\
\text { MESAP }\end{array}$ \\
\hline
\end{tabular}

Classification criteria have been oriented by the classification presented in chapter 2; additionally energy planning systems/model sets have been included in the classification cluster. The analysis is structured into two parts. The first part deals with global information on the methodologies, time frame, applications of the model and hard- and software requirements. The second part focuses on specific aspects, which are relevant in the context of energy planning in developing countries such as the rural/urban dichotomy, analytical representation of non-commercial fuels, potential of renewable energy, regional imbalances, interaction between energy and economy and foreign exchange requirements. 
The time horizon of most models is medium- or long term. The spatial frame covers specific countries or a group of countries in a defined region.

The most frequent methodologies applied are process- engineering and econometrics for demand models, simulation and optimization for supply models, a combination of input-output technique and simulation or optimization for energy-economy models and a set of different techniques for energy planning system/model sets.

The field of application for most of the models is still small due to the fact, that energy models have been introduced to energy planning in developing countries only some years ago. Due to available documentation, exceptions are the demand model "MAED", of the IAEA and "MEDEE" of the University of Grenoble as well as the electricity supply system model "WASP" of the IAEA. Most models were developed and designed for mainframe computers. Recently the implementation of mainframe programs on microcomputers has been commenced. Other developments make use of microcomputer specific characteristics and commercial software and program their models for microcomputer applications exclusively. Especially some energy planning systems gained from this trend.

The developing country specific criteria of the evaluation which deserved our particular attention, are commented below.

\section{The Rural-Urban Dichotomy}

The urban sectors depend in most cases strongly on the consumption of the so-called commercial fuels, while the rural population depends, in some cases, almost entirely on traditional forms of energy (non-commercial fuels). The latter leads to severe problems such as deforestation, erosion, loss of soil fertility and traditional farmland.

There are two reasons why the non-commercial fuel should be treated differently from the commercial ones. First they are by and large untraded and fall outside the normal cash transactions aside from areas near the urban centers, where especially firewood is traded. Secondly, for commercial fuels the suppliers and consumers are distinct entities while the consumers and suppliers of non-commercial fuels are the same. There exists a difficult quantification problem for the noncommercial fuels.

In most of the models, that treat non-commercial fuels, only fuelwood is considered in detail, because it is the largest form consumed and the inclusion of animal dung, crop residue, twigs and leaves will greatly complicate an already complex structure. Some models miss the point by non recognizing this rural-urban dichotomy present in most developing countries. An example of a good representation of the rural-urban differences is given by the LEAP model.

\section{Analytical Representation of Non-Commercial Fuels}

This section deals with models which represent analytically the supply and demand of noncommercial fuels. Among the models, two approaches are used to analytically handle the supply of non-commercial fuels.

The first method concerns the network approach which is used by most supply optimization models. The principle is to find the "optimal" supply structure for non-commercial energy, given the availability of necessary technology and cost data. Cost data, of course represent in many cases opportunity costs, since there are no direct costs available. The time devoted to wood collection may for example be expressed in a monetary opportunity cost value. The second method, implemented for instance in ENERPLAN, approaches the supply of fuelwood from a resource balance equation. The total available forestry resource stock at a given time is equated to the available stock at a previous time step, plus incremental addition due to afforestation and natural growth of the forest resource in that period, less the consumption and deforestation due to other causes in the same period. 


\section{Potential of Renewable Energy}

Many developing countries are endowed with a large resource base of renewable energy sources. These sources include resources such as hydropower, solar energy, wind, tidal, geothermal, biomass, etc.

The potential of renewable energy sources for satisfying energy demand can principally be analyzed by all energy supply models reviewed in this study. The representation of renewable sources in energy supply models such as MESSAGE, requires, however, very detailed information about resources and conversion technologies, which is generally not available. In addition, the amount and availability of renewable sources depend largely on climatic conditions, which has to be taken into account in such supply models.

\section{Regional Imbalance}

Most developing countries are characterized by a heterogenous spatial development. The economic and social infrastructure are distributed unevenly. While some regions are heavily industrialized, others have subsistence economy. Differences in economic development of various parts of a country often result in different regional levels of energy demand. As a result, energy is also distributed unevenly in the regions. Lack of energy supply systems in underdeveloped regions has often led to lack of investment in those areas.

Many of the energy supply models reviewed represent the technical dimension of the energy system only. Homogeneity throughout the country or region is assumed implicitly. The application of such models for a larger developing country requires often modifications in order to add the regional dimension.

\section{Management of Exhaustible Resources}

Management of exhaustible resources is an important issue in most developing countries and has considerable direct or indirect impact on the economic development. Optimal utilization of resources and development of an appropriate resource pricing policy will either contribute to the increase of foreign exchange revenues (from the export of these resources) or to the decrease of energy imports, and consequently helps to reduce foreign exchange requirement.

The energy supply system models, which have been reviewed, use optimization techniques. In these models, the export revenues from energy are negative contributions to the objective function. In the case of a large oil exporting developing country this modelling feature would lead to false conclusions for the domestic market. It would, therefore, be necessary to analyze the utilization of exhaustible resources for the domestic and for the export market separately.

\section{Interaction Between Energy and Economy}

Understanding the relationship between the energy sector and the rest of the economy is important in two aspects. First, the energy sector is linked with almost all the sectors of the economy, hence economic activities will have a large influence on the energy demand. Secondly, an energy planning exercise is not an objective in itself but rather a means of achieving national development objectives. For developing countries in particular, the interaction between the energy sector and the economy assumes a bigger dimension since the singular objective of these countries is that of achieving balanced development within the shortest feasible period.

There are three different techniques used in the energy-economy models reviewed: The first method bases on linear programming using input-output tables as input. This is the technique adopted for instance by the TEESE model, which was structured and developed around the Brookhaven Energy Economy Assessment Model (BEEAM). 
The second major method is somewhat different from the first approach because there is no optimization but rather simulation of the economy under the assumptions of various alternative policies. This was the approach used by the Blitzer model of the energy-economy in Jordan. This type of model is basically built around variables such as GNP, investment and savings.

The third methodology is applied by the so-called Computable General Equilibrium Models (CGEM). The CGEM are based on the original Walrasian equilibrium in which prices are adjusted to make excess demand equal to zero, such that consumers maximize their utility functions while the producers maximize profits.

\section{Foreign Exchange Requirements}

The developing countries are usually characterized by underdeveloped industrial infrastructures. Expansion of any sector of the economy will require importation of technology from industrialized countries.

The energy sector is a large scale system. Development of this sector requires the construction of large extraction and conversion technologies, which are usually, to different extends, not within the technological capabilities of most developing countries. Therefore, a large sum of foreign exchange will have to be allocated for the importation of the necessary extraction, conversion and transmission facilities.

In addition, net energy importing developing countries have to spend foreign exchange for importation of fuels, which is needed by the energy system. Foreign exchange expenditures on importation of fuels and technologies are important issues. In most developing countries, the availability of foreign exchange is a major problem and may limit the development of the energy sector. A flexible tool for planning the energy system must have the capability of being used to analy the effect of foreign exchange shortages on the structure of the energy system.

The objective function of reviewed energy supply system models, like EFOM or MARKAL, is usually minimization of total cost. This total cost is the sum of domestic costs and the foreign exchange expenditure for operating and developing the energy sector. For analysis of the foreign exchange requirement, it will be necessary to specify the domestic and foreign components of the total cost in the objective function explicitly.

\section{CONCLUSIONS AND RECOMMENDATIONS}

From the model review the following conclusions can be drawn. On the problem of data, it is clear that the lack of reliable and consistent data in most developing countries limits the usefulness of some of the more comprehensive and detailed models. Apart form the problem of data, those models, which utilize econometric techniques have an additional complication due to the structural change and economic/political disequilibrium ever present in developing countries. Yet, despite these problems, if models are to serve as a useful aid for decision making, there may be no choice but to dedicate more efforts to the data collection on a more frequent basis. In the interim, "educated guesses" or cross-country comparisons may be used, albeit with great care in estimating input parameters.

On the major problem of inadequate representation of the rural energy system, some models simply miss the point by not recognize the rural/urban dichotomy present in most developing countries. Those, that do recognize this structure deal with the rural energy system inadequately. The source of this problem is twofold: First, the lack of data leads to oversimplifications of the problem; secondly, it must be recognized, that the rural energy system is complex and has from the methodological point of view not been extensively covered. Problem areas, which are worth mentioning here are: monetary valuation of non-commercial fuels, different end-use purposes for the traditional fuels (also non-energetic ones like the use of wood for construction or the use of crop residues for fertilization), the distinction between provision and requirement for traditional 
fuels in rural regions, the ecological impacts, which are associated with the use of traditional fuels and the problem of intertemporal allocation of limited resources.

In view of the above observations, it becomes obvious, that there is a need for more efforts in the direction of data collection and institutionalization of these efforts in the developing countries. Computerized planning tools can help to establish a common basis of understanding among the different experts form different disciplines working on the same energy planning issue, since computerized tools make it easier to discuss the same data base and the results, which were based on the same methods and tools.

Most computerized energy planning tools may not be called user friendly so far. Keeping in mind, that these tools will only be used in the long run, if they are well documented and user friendly in the broadest sense of the word, one will have to put much more emphasis on a proper documentation, comfortable user-interfaces and effective training schedules, if the energy planning exercise should not remain a "one time" activity, but an ongoing task.

Summarizing the aforesaid, it can be concluded that an adequate computerized energy planning tool should meet the following requirements:

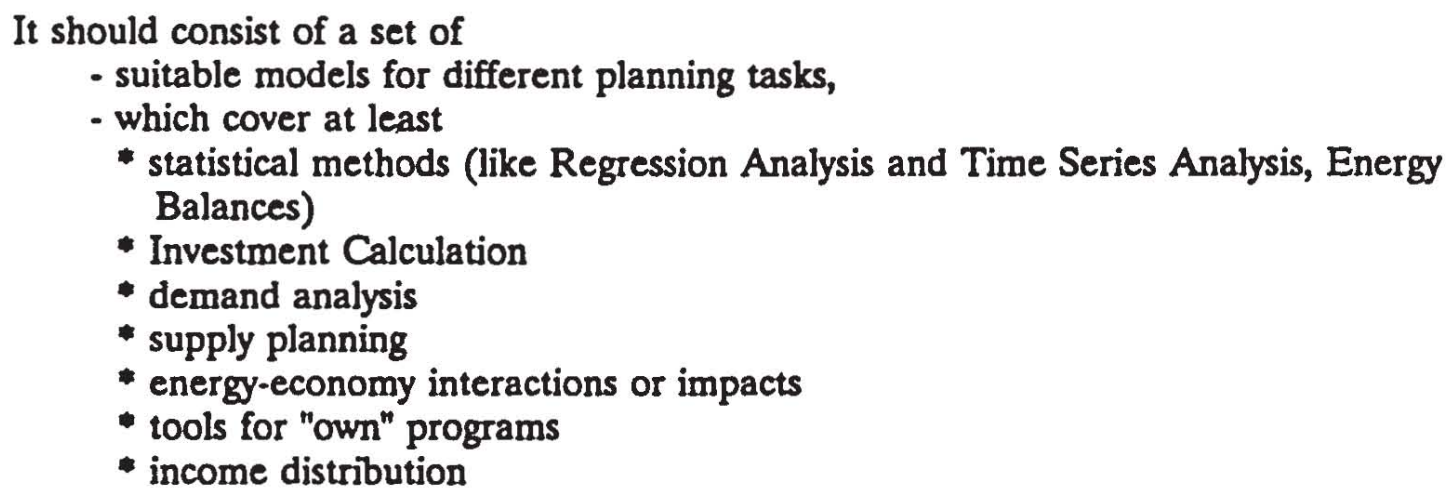

- a user friendly data management system for the data, file and program organization

- a data base, where key-data can be stored on a central place

- a low cost, high capacity microcomputer system including peripheric equipment for proper presentation of the results

- a graphic, interactive presentation package

The models should - reflect the developing country specific problems in the energy field as

- rural/urban dichotomy

- representation of non-commercial fuels

* consideration of regional imbalances

* management of exhaustible resources

- interaction between energy and economy

- have access to a common control data base to avoid inconsistencies

- be transparent concerning their operations

- be designed for interactive operation

- user and operator friendly

- be well documented

- be flexible to respond quickly to changed situations

- be portable from one computer system to another-independent of the operating system 


\section{REFERENCES}

VoB, A., A. Adegbulugbe, F. Dayo, A. Reuter, Y. Saboohi, and S. Rath-Nagel (1986). "Models as Decision Support Tools for Energy Planning in Developing Countries," Presented at 8th Annual International Conference of the LAEE, Tokyo.

Rath-Nagel, S., and A. VoB (1981). "Energy Models for Planning and Policy Assessment," European Journal of Operations Research, vol. 8, North Holland Publishing Company.

Reuter, A (1986). MESAP Manual, IKE-DC-86/1.

Reuter, A. (1987). "Tools for Energy Planning," Presented at the UNDP/World Bank Seminar, Energy Planning: The Prospects and Challenges that Lie Ahead, Vienna. 